\title{
LEVANTAMENTO VISUAL DAS PATOLOGIAS DO SISTEMA VIÁRIO DO CAMPUS UNIVERSITÁRIO DA UFAM EM MANAUS - AM
}

\author{
DE OLIVEIRA DUTRA, MATHEUS \\ Graduando em Engenharia Civil \\ Universidade Federal do Amazonas - UFAM \\ Amazonas; Brazil \\ dutra.matheus96@gmail.com
}

\author{
OLIVEIRA LOPES, MESSIAS \\ Mestrando em Engenharia Geológica \\ Universidade de Évora - UEVORA \\ Évora; Portugal \\ editor.agape@bol.com.br
}

\author{
VINICÍUS PALHETA DE SOUZA, LUCAS \\ Graduando em Engenharia Civil \\ Universidade Federal do Amazonas - UFAM \\ Amazonas; Brazil \\ lucas.9810@hotmail.com
}

\section{RESUMO}

O Campus da Universidade Federal do Amazonas (UFAM), em Manaus, apresenta patologias recorrentes em seu pavimento. Desta maneira, com o intuito de identificar e caracterizar possíveis falhas de execução e/ou projeto, fez-se um breve levantamento de sua estrutura, analisando o projeto de ampliação das vias, executado na década de 1980. Ainda para atestar a atual situação do pavimento, sucedeu-se por levantamento visual das patologias presentes no sistema viário do campus. Utilizou-se, em campo, as diretrizes técnicas do Departamento Nacional de Infraestrutura e Transporte (DNIT) e de estudos de caracterização do solo regional anteriormente realizados. Por fim, simplificaram-se os resultados obtidos a partir do levantamento visual e da análise teórica realizada em Valores de Serventia Atual (VSA) do pavimento, classificando o atual estado das vias, a variar, nominalmente, de ruim a bom, indicando, em alguns trechos, que a segurança e o conforto dos usuários estão comprometidos. Palavras-chave: sistema viário, pavimento, patologias, Valores de Serventia Atual (VSA).

\section{ABSTRACT}

Located in Manaus, the Federal University of Amazonas' Campus presents recurrent pathologies on its pavement. By doing this, with the purpose of identifying possible failures or mistakes of execution and/or design, a brief survey of its structure was conducted, analyzing the roads extension project executed in the 80's. In order to attest the current pavement condition, a visual survey of the present pathologies on the campus' road system was realized. In the field, the methodology considered the technical specifications of the Infrastructure and Transport National Department (DNIT) and previous studies about the local soil. Lastly, the results obtained were simplified using visual survey and the theorical analysis fulfilled in Current Service Roads Values (VSA), classifying routes' actual situation, from poor to good, indicating that users' safety and comfort are impaired.

Keywords: road system, pavement, pathologies, Current Service Roads Values (VSA).

\section{INTRODUÇÃO}

Sistema viário é um conjunto de vias que tem por função atender ao tráfego de veículos com serventia, segurança e conforto. No entanto, para o cumprimento de tal função, deve-se ater para alguns fatores limitadores no desempenho de mobilidade das vias: função social, impactos ambientais, desenvolvimento econômico e aspectos relacionados à infraestrutura dos pavimentos. Onde, em grande parte dos casos, esse último é a causa do mau desempenho das vias. Tal fato pode ser observado, principalmente, por meio da opinião dos usuários que trafegam por essas estruturas.

Na visão de Bernucci et al. (2008), os pavimentos podem ser descritos como estruturas de múltiplas camadas construídas com o objetivo de resistir aos esforços provenientes do tráfego de veículos, assim como, proporcionar aos usuários segurança e conforto de rolamento. Sendo que, para garantir tais finalidades, deve-se assegurar a regularidade 
da superfície da camada de revestimento, corrigindo patologias e irregularidades, mitigando suas causas. Conforme o DNIT (2006), pavimentos com alto grau de irregularidades, além de não proverem suavidade de rolamento, tendem a gerar custos operacionais aos usuários, perca de serventia, como também, redução de sua vida útil.

A experiência de campo tem demonstrado que o sucesso das obras de pavimentação está diretamente ligado ao planejamento e controle tecnológico empregado nas fases de projeto, nas que antecedem à execução, na própria realização do pavimento, e no seu comportamento ao longo da vida útil de serviço (DNIT, 2006; FONSECA, 2016). Desse modo, para que se obtenha um bom desempenho de um pavimento, é fundamental boa prática em todas as etapas da concepção de um pavimento, que podem ser obtidas respeitando os requisitos técnicos estabelecidos pelas normas técnicas e diretrizes dos órgãos atinentes ao tema. Deve-se ater também aos casos excêntricos, aqueles que de alguma maneira tendem a apresentar inconsistências e patologias em detrimento dos métodos e premissas consagradas, necessitando de sensibilidade nas tomadas de decisão.

Atualmente, novas metodologias e materiais estão sendo pesquisados e desenvolvidos pelo setor privado e pelas entidades públicas, essas representadas pelas universidades, visando a melhoria da qualidade dos pavimentos, principalmente, no que diz respeito às pistas de rolamento. Assim, identificar e caracterizar as causas das patologias presentes nos pavimentos dos sistemas viários é de suma importância para a criação de inovações beneficiadoras, visto que soluções são desenvolvidas em decorrência de problemas.

As literaturas técnicas abordam diversas maneiras de medir as condições de uma superfície. A sensibilidade de avaliação é comparada diretamente ao método que, em grande parte, está relacionado com as percepções dos usuários. Nesse sentindo, elenca-se o Valor de Serventia Atual (VSA), que é uma medida subjetiva das condições do pavimento, feita por um grupo de avaliadores que percorrem a via sob análise, registrando suas opiniões sobre a capacidade do pavimento de atender às exigências oriundas do tráfego no momento da avaliação, quanto à suavidade e ao conforto (DNIT, 2003 ${ }^{\mathrm{c}}$.

Desta maneira, o presente trabalho tem por objetivo levantar as patologias do pavimento do Campus da UFAM e atestar suas condições atuais por meio do resultado proveniente do cálculo do VSA para o pavimento em questão. Para tal, utilizou-se as diretrizes do Departamento Nacional de Infraestrutura e Transporte (DNIT) para realização de uma inspeção em campo, seguida da análise do projeto de ampliação do pavimento e coleta de informações com alguns dos responsáveis pela gestão do campus.

\section{HISTÓRICO DO SISTEMA VIÁRIO DO PAVIMENTO DO CAMPUS UNIVERSITÁRIO DA UFAM}

Em um breve relato obtido por meio de entrevista realizada no mês de novembro do ano de 2018 com o professor Dr. Atlas Augusto Bacellar, pertencente ao corpo de docentes da universidade em estudo, projetista de rodovias e exprefeito do campus, levantou-se o histórico do pavimento do sistema viário da UFAM, evidenciando os períodos e acontecimentos em que houveram mudanças significativas dentro do âmbito que o presente trabalho se propôs a pesquisar.

A narrativa teve como ponto de partida relatos da década de 80, quando o campus universitário da UFAM dispunha somente de edificações situadas no setor sul, área denominada de mini campus. Em função de se evitar invasões da área que abrange parte do campus universitário e com a demanda por qualificação acadêmica, originou-se a necessidade de uma ocupação estratégica para preservar e garantir a ocupação do espaço, resultando na ampliação de unidades construídas no setor norte, acontecimento que resultou no projeto geométrico da estrada que hoje interliga os setores norte e sul da universidade, ressaltando-se que o projeto contemplava inicialmente uma única fila por sentido de trânsito.

Até 1984, as vias existentes no campus ainda não haviam recebido camadas de revestimento asfáltico. Nesse mesmo período, suscitou-se a necessidade de ampliação das mesmas, de modo que cada sentindo passasse a ter duas filas, bem como, a execução da pavimentação asfáltica da rodovia existente. A realização de tais projetos foi possível devido ao financiamento adquirido pelo governo federal junto ao Banco Interamericano de Desenvolvimento (BID), sendo que os serviços foram executados pela divisão de engenharia da Comissão de Aeroportos da Região Amazônica (COMARA). No entanto, as faixas decorrentes da ampliação não receberam pavimentação asfáltica, somente a estrutura que já existia foi beneficiada. Para a execução do asfaltamento, compreendido na parte central da estrada, executou-se a compactação do subleito, seguido de imprimação e execução da capa de rolamento que foi realizada com Areia Asfáltica Usinada a Quente (AAUQ), permanecendo desta maneira ao longo de 16 anos. 
No ano de 2000 após longo tempo de serviço das vias, sem que houvesse nenhuma intervenção significativa no que diz respeito à correção das patologias que passaram a comprometer o desempenho do pavimento, docentes que compunham o corpo técnico da UFAM, especialistas na área que abrange a construção de estradas, mobilizaram-se na elaboração do projeto de recuperação da rodovia do campus.

Em 2001, as obras foram licitadas e iniciadas pela empresa vencedora do certame. Incialmente, estavam previstos a regularização de áreas que demandassem correções, execução de uma base em solo-brita com espessura de $20 \mathrm{~cm}$ e pavimentação dos dois bordos, contudo, a empresa não teve condições financeiras de prosseguir com os serviços, os quais foram iniciados e em seguida paralisados.

No ano seguinte, houve intervenção política na situação instaurada no campus, o que possibilitou a transferência dos serviços para outra empresa. A obra foi retomada e finalizada ainda em 2002. No entanto, as práticas de execução mudaram, a nova prestadora de serviços detinha uma máquina recicladora de pavimento e lhe foi permitido que o material reciclado proveniente do pavimento existente passasse a compor a base. É importante salientar que o material reciclado só foi utilizado na execução da parte central da via, nas filas laterais, criadas posteriormente, seguiu-se as especificações iniciais previstas no projeto. Também se chama a atenção para falhas de projeto evidenciadas posteriormente à conclusão das obras, sendo talvez a drenagem uma das principais. Além do acréscimo da contribuição de vazão decorrentes das novas edificações que não foram previstas na drenagem inicial, algumas canalizações estão posicionadas nas cotas mais altas, ao invés de estarem nas cotas mais baixas.

Mesmo com tais falhas de projeto, patologias e, aumento dos esforços oriundos do crescimento do fluxo de veículos que percorrem as vias do campus, até aos dias de hoje, boa parte do pavimento existente, é o mesmo do que fora construído no ano de 2002. Apenas alguns trechos da estrada foram recuperados totalmente, enquanto que a maior parte recebeu apenas correções paliativas. Por fim, ressalta-se que as manutenções preventivas não são práticas comuns, e que a estrutura não tem recebido a atenção necessária, ultrapassando-se os 10 anos de vida útil prevista para o pavimento sem que houvesse a recuperação total do mesmo.

\section{PAVIMENTO}

Segundo Senço (2008), pavimento é uma estrutura construída sobre a terraplanagem, destinada a resistir e distribuir os esforços originados do tráfego, melhorar as condições de rolamento quanto ao conforto e segurança e suportar as ações oriundas de esforços horizontais, tornando a superfície de rolamento mais durável. Barbosa (2016) descreve o pavimento como uma estrutura formada por várias camadas de espessuras finitas, capazes de resistir aos esforços do tráfego e do meio ambiente, sendo que o desempenho dessa composição está relacionado às propriedades físicas e mecânicas dessas camadas.

As diferentes camadas que formam um pavimento são denominadas conforme a sua posição, que varia da fundação à superfície. Tomando-se como referência a superfície, tem-se a camada de rolamento como a primeira das camadas, seguida respectivamente pelas camadas de base, sub-base, reforço do subleito, e subleito. Ressalta-se que nem todo pavimento precisa ser, necessariamente, composto de todas essas camadas, uma vez que cada projeto apresenta particularidades quanto a sua estrutura e funcionalidade.

Para fins de projetos de pavimentos, é necessário considerar algumas premissas que influenciam diretamente na viabilidade dos mesmos. Segundo Moura (2014), um bom pavimento deve atender, necessariamente, três requisitos básicos: 1- Conforto ao usuário; 2- Segurança ao usuário: 3- O projeto deve apresentar uma solução técnica que conduza a uma execução com menor custo para implantação da obra.

Além das premissas levantadas por Moura, salienta-se que também há necessidade de se considerar os aspectos ambientais como fatores para viabilização de projetos, tendo em vista que tradicionalmente o uso de recursos naturais se dá de forma indiscriminada nas obras de construção civil.

\subsection{Revestimento asfáltico}

A camada de rolamento, ou revestimento como também é conhecida, tem a função de transmitir os esforços oriundos das ações de tráfego para as camadas inferiores. Esses revestimentos podem ser classificados de três maneiras: flexível, 
semirrígido e rígido. Conforme dados levantados pelo CNT (2016), no Brasil os pavimentos do tipo flexível representam mais de $99 \%$ da malha rodoviária pavimentada.

Comumente executado pela economia no custo da obra e velocidade na execução, os pavimentos flexíveis segundo o DNIT (2006), são aqueles em que todas as camadas sofrem deformação elástica significativa devido ao carregamento aplicado, logo, a carga tende a se distribuir em parcelas aproximadamente equivalentes entre as múltiplas camadas que constituem o pavimento.

A composição usual dos revestimentos flexíveis compreende a mistura de quatro elementos: o agregado graúdo, agregado miúdo, material de enchimento e ligante betuminoso, sendo o Cimento Asfáltico de Petróleo (CAP) o mais utilizado. Esse conjunto é denominado de Concreto Asfáltico (CA). É importante frisar que em misturas asfálticas, a composição, principalmente ao que tange aos agregados, influencia em quase todas as propriedades importantes da mistura, como a rigidez, a durabilidade, a permeabilidade, a trabalhabilidade e a resistência à fadiga.

Cavalcante et al. (2012), em seu estudo verificou para o caso específico da cidade de Manaus, o uso de seixo rolado como agregado graúdo em mistura do tipo CA, a utilização de misturas betuminosas do tipo Areia Asfáltica Usinada a Quente (AAUQ), ou a ausência de agregados graúdos sobre base e sub-base com predominância de material argiloso, propicia a formação de patologias, principalmente trincas, fissuras e panelas.

Elenca-se ainda, algumas literaturas importantes no que diz respeito à busca contínua de alternativas que visam adequar o revestimento asfáltico às circunstâncias regionais: CAVALCANTE et al. (2010); FROTA et al., 2006 ${ }^{\text {; }}$ FROTA et al., 2006b; FROTA et al., 2007ª; FROTA et al., 2007b; FROTA et al., 2007c; FROTA et al., 2007d.

\subsection{Tipos de patologias em pavimentos}

As causas mais recorrentes de patologias devem-se por falta de planejamento e controle, que em grande parte, tem relações com: a) falha na determinação dos materiais que comporão as camadas do pavimento, ora por não serem disponíveis na região, ou por não atenderem os requisitos do projeto; b) falha nos estudos de laboratório, uma vez que esses estão sujeitos a inexatidão proveniente da reprodução das condições de campo; c) falha nas especificações dos materiais, tendo em vista que cada região possui suas peculiaridades, como por exemplo a temperatura; d) falha nos procedimentos de execução, oriunda da falta de capacidade técnica dos funcionários, como também do controle tecnológico empregado, e entre outras.

Contudo, apesar de serem inúmeras as causas de degradação dos pavimentos e seus respectivos mecanismos de ação, há patologias mais recorrentes nos pavimentos. Especificações do DNIT $\left(2003^{\mathrm{a}}\right)$ definem as terminologias designadas na representação de patologias em pavimentos quanto ao seu grau de severidade (Figura 1).

\begin{tabular}{|c|c|c|c|c|c|c|}
\hline \multicolumn{5}{|c|}{ NATUREZA DA OCORRÊNCIA } & \multirow{2}{*}{\multicolumn{2}{|c|}{ NOTAÇÃO }} \\
\hline \multicolumn{5}{|c|}{ Ausência aparente de falhas na superficie do revestimento } & & \\
\hline \multirow{10}{*}{ 空 } & \multirow{7}{*}{$\begin{array}{c}\text { Trincas no } \\
\text { revestimento geradas } \\
\text { por deformação } \\
\text { permanente excessiva } \\
\text { e/ou decorrentes do } \\
\text { fenômeno de fadiga }\end{array}$} & & ISSURAS & & FI & \multirow{5}{*}{ FC-1 } \\
\hline & & \multirow{4}{*}{$\begin{array}{l}\text { Trincas } \\
\text { isoladas }\end{array}$} & \multirow{2}{*}{ Transversais } & Curtas & TTC & \\
\hline & & & & Longas & TTL & \\
\hline & & & \multirow{2}{*}{ Longitudinais } & Curtas & TLC & \\
\hline & & & & Longas & TLL & \\
\hline & & \multirow{2}{*}{$\begin{array}{l}\text { Trincas } \\
\text { interligadas }\end{array}$} & \multirow{2}{*}{ "Jacaré" } & $\begin{array}{l}\text { Sem erosão acentuada nas } \\
\text { bordas das trincas }\end{array}$ & $\mathrm{J}$ & FC-2 \\
\hline & & & & $\begin{array}{l}\text { Com erosão acentuada nas } \\
\text { bordas das trincas }\end{array}$ & $\mathrm{JE}$ & FC-3 \\
\hline & \multirow{3}{*}{$\begin{array}{c}\text { Trincas no } \\
\text { revestimento não } \\
\text { atribuídas ao } \\
\text { fenômeno de fadiga }\end{array}$} & $\begin{array}{l}\text { Trincas } \\
\text { isoladas }\end{array}$ & \multicolumn{2}{|c|}{$\begin{array}{l}\text { Devido à retração térmica ou dissecação da } \\
\text { base (solo cimento) ou revestimento }\end{array}$} & TRR & FC-1 \\
\hline & & \multirow{2}{*}{$\begin{array}{c}\text { Trincas } \\
\text { interligadas }\end{array}$} & \multirow{2}{*}{ "Blocos" } & $\begin{array}{l}\text { Sem erosão acentuada nas } \\
\text { bordas das trincas }\end{array}$ & TB & FC-2 \\
\hline & & & & $\begin{array}{l}\text { Com erosão acentuada nas } \\
\text { bordas das trincas }\end{array}$ & TBE & FC-3 \\
\hline \multirow{4}{*}{ 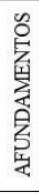 } & \multirow{2}{*}{ Plásticos } & Locais & \multicolumn{2}{|c|}{$\begin{array}{l}\text { Devido à fluência plástica de uma ou mais } \\
\text { camadas do pavimento e/ou do subleito }\end{array}$} & \multicolumn{2}{|c|}{ ALP } \\
\hline & & $\begin{array}{c}\text { Trilhas de } \\
\text { rodas }\end{array}$ & \multicolumn{2}{|c|}{$\begin{array}{l}\text { Devidos à fluência plástica de uma ou mais } \\
\text { camadas do pavimento e/ou do subleito }\end{array}$} & \multicolumn{2}{|c|}{ ATP } \\
\hline & \multirow{2}{*}{ De consolidação } & Locais & \multicolumn{2}{|c|}{$\begin{array}{l}\text { Devidos à consolidação diferencial ocorrente } \\
\text { em camadas do pavimento e/ou do subleito }\end{array}$} & \multicolumn{2}{|c|}{ ALC } \\
\hline & & $\begin{array}{c}\text { Trilhas de } \\
\text { rodas }\end{array}$ & \multicolumn{2}{|c|}{$\begin{array}{l}\text { Devidos à consolidação diferencial ocorrente } \\
\text { em camadas do pavimento e/ou do subleito }\end{array}$} & \multicolumn{2}{|c|}{ ATC } \\
\hline \multicolumn{5}{|c|}{ Corrugação-Ondulações } & \multicolumn{2}{|c|}{$\mathrm{O}$} \\
\hline \multirow{2}{*}{\multicolumn{5}{|c|}{$\begin{array}{c}\text { Escorregamento } \\
\text { Exsudação }\end{array}$}} & & \\
\hline & & & & & \multicolumn{2}{|c|}{ EX } \\
\hline \multicolumn{5}{|c|}{ Desgaste } & \multicolumn{2}{|r|}{ D } \\
\hline \multicolumn{5}{|c|}{ "Panelas" } & \multirow{2}{*}{\multicolumn{2}{|c|}{$\begin{array}{l}\mathrm{P} \\
\mathrm{R}\end{array}$}} \\
\hline & Remend & os existentes (s & superficial ou $\mathrm{p}$ & rofundos) & & \\
\hline
\end{tabular}

Figura 1: Termos técnicos aplicáveis aos defeitos dos pavimentos. Fonte: Google DNIT, 2003ª 


\section{MATERIAIS E MÉTODOS}

O presente estudo classifica-se, quanto aos objetivos, como descritivo e explicativo e, quanto aos procedimentos para coleta de dados, realizou-se vistorias in loco, no período que compreende o mês de novembro de 2018, no local da pesquisa.

\subsection{Local da Pesquisa}

Pertencente a Área de Proteção Ambiental - APA UFAM, o Campus Senador Arthur Virgílio Filho (Figura 2), da Universidade Federal do Amazonas, que fica na cidade de Manaus, é o terceiro maior fragmento nativo de floresta do mundo e o maior do Brasil, perfazendo uma área total de 6,7 milhões de metros quadrados (DUTRA et al., 2017).

O acesso ao campus só é possível pela Avenida General Rodrigo Otávio. A extensão da malha rodoviária da universidade é de aproximadamente 7,0 km (Prefeitura do Campus, 2017), sendo 800 metros a distância da Avenida General Rodrigo Otávio até o setor sul, e de 3,6 km até o setor norte, utilizando-se as paradas internas como referência desses intervalos de distância. $\mathrm{O}$ único modal utilizado no acesso ao campus é o rodoviário, que pode ser particular ou coletivo, respectivamente, representados por carros de passeio e ônibus que atuam em linhas circulares e de integração.

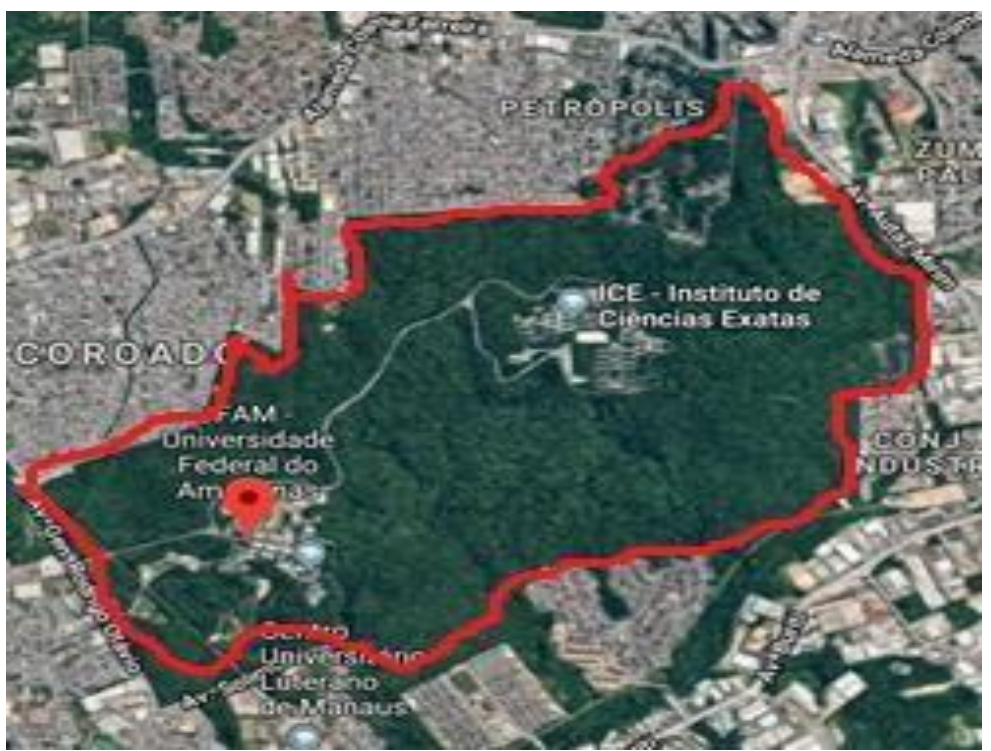

Figura 2: Imagem da UFAM obtida por meio de Sátelites. Fonte: Google Maps, 2018.

\subsection{Materiais}

Uma vez que neste estudo buscou-se levantar as patologias do sistema viário da UFAM por meio de processo visual, não se fez necessário o uso de muitas tecnologias e/ou aparelhagens. Contudo, para que a análise do pavimento fosse possível, teve-se que utilizar os seguintes materiais: caneta, papel, trena de 50 metros, máquina fotográfica, carro de passeio e, aparelho com Sistema de Posicionamento Global (GPS).

\subsection{Métodos}

Para realização do trabalho foram utilizadas como metodologia as especificações consagradas do DNIT, especificamente, as normativas 005/2003 - PRO, 008/2003 -PRO e 009/2003 - PRO, e estudos pertinentes a esta abordagem, realizados anteriormente por Cavalcante et al. (2012), e Ribeiro et al. (2017).

DNIT $\left(2003^{\mathrm{a}}\right)$, trata dos defeitos nos pavimentos flexíveis e semi-rígidos. Já em DNIT (2003b), estabelece-se o procedimento para o levantamento visual contínuo com a finalidade de avaliação da superfície de pavimentos flexíveis e semirrígidos. Por fim, DNIT (2003c), elenca o procedimento para a avaliação subjetiva da superfície de pavimentos flexíveis e semi-rígidos. Com base nas descrições contidas nas literaturas citadas, utilizadas como base para elaboração desta pesquisa, criou-se o seguinte fluxo (Figura 3) para exemplificar o procedimento adotado no processo de avaliação das patologias: 


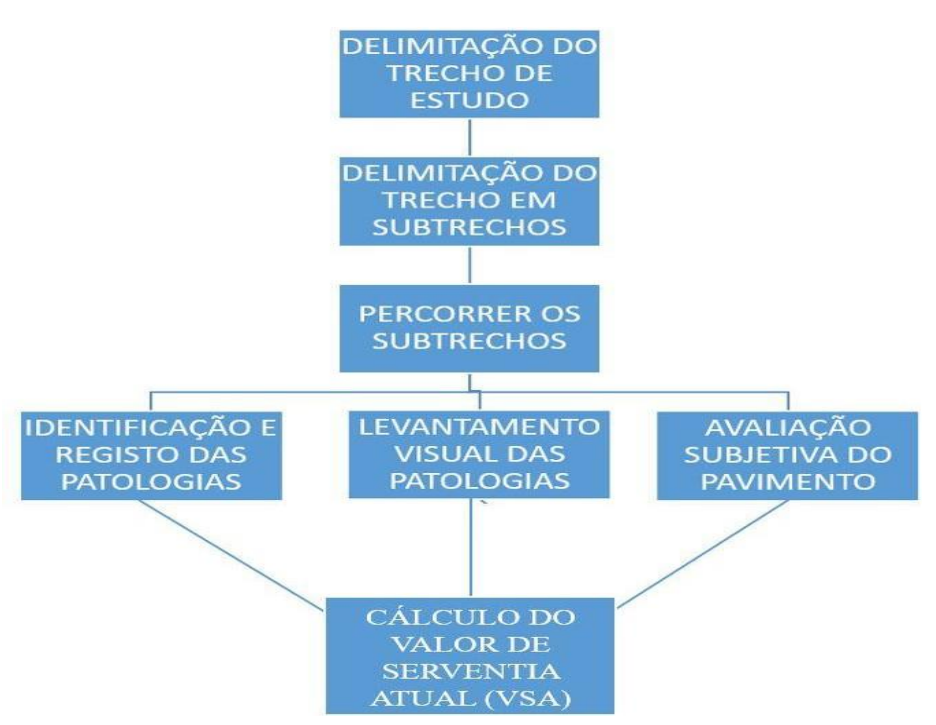

Figura 3: Fluxo do procedimento de avaliação. Fonte: Autores, 2018.

Na etapa que compreendeu a delimitação do trecho de estudo, considerou-se algumas peculiaridades presentes no sistema viário da universidade. Inicialmente, levantou-se as extensões da malha que apresentavam aspectos bastante uniformes quanto aos defeitos existentes, conforme recomendação do DNIT (2003b). Deste modo, as extensões que recentemente receberam serviços de recuperação total e/ou aquelas que apresentam baixo tráfego, foram desconsideradas. Em seguida, dividiu-se o trecho em 7 subtrechos (Figura 4), com aproximadamente 600 metros cada, demarcando o início e o fim de cada um deles, conforme especificações elencadas em DNIT (2003c).

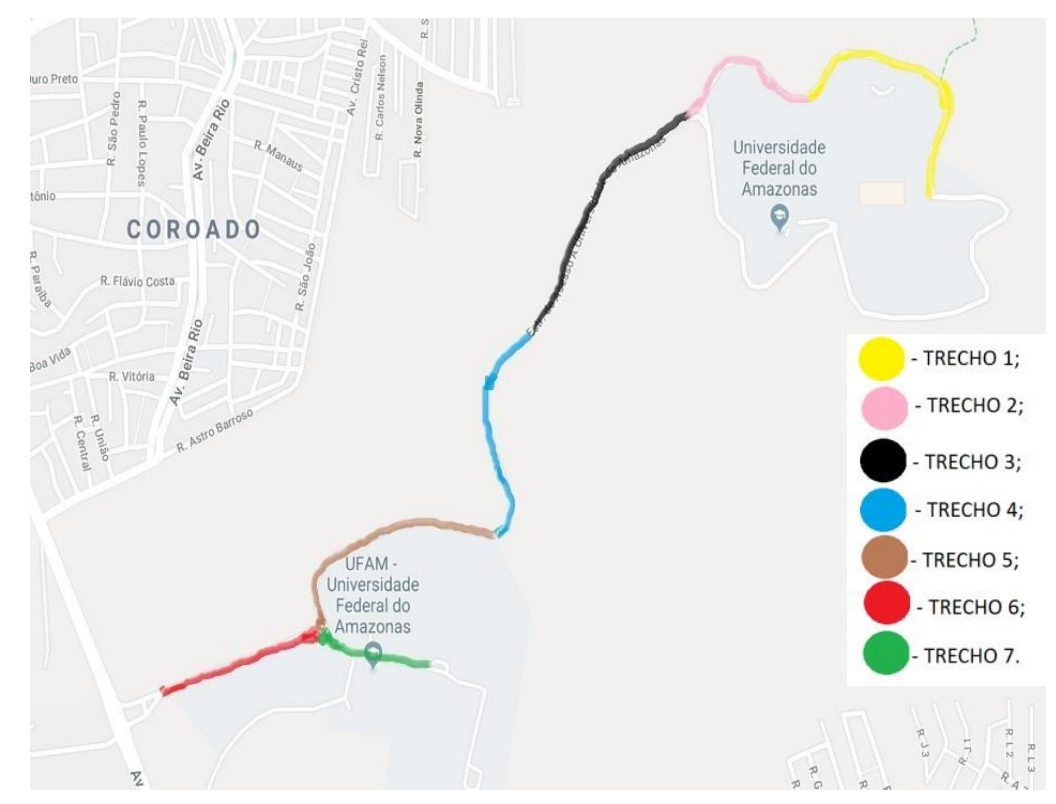

Figura 4: Divisão dos Subtrechos. Fonte: Adaptado de Google Maps, 2018.

Após as delimitações, tomou-se como ponto de referência para o prosseguimento do procedimento de avaliação a parada situada na entrada do Instituto de Filosofia, Ciências Humanas e Sociais (IFCHS). Então, percorreu-se os subtrechos em um veículo operado na velocidade média aproximada de $40 \mathrm{~km} / \mathrm{h}$, fazendo-se a avaliação visual, como também, a identificação e registro das patologias. Ressalta-se que, por se tratar de rodovias com duas pistas de cada lado, realizou-se o trajeto em ambos os sentidos do trecho. Para avaliação subjetiva do pavimento, partiu-se dos estudos de Cavalcante et al. (2012), que utilizou-se da ficha de avaliação (Figura 5) contida nas diretrizes do DNIT (2003c). 

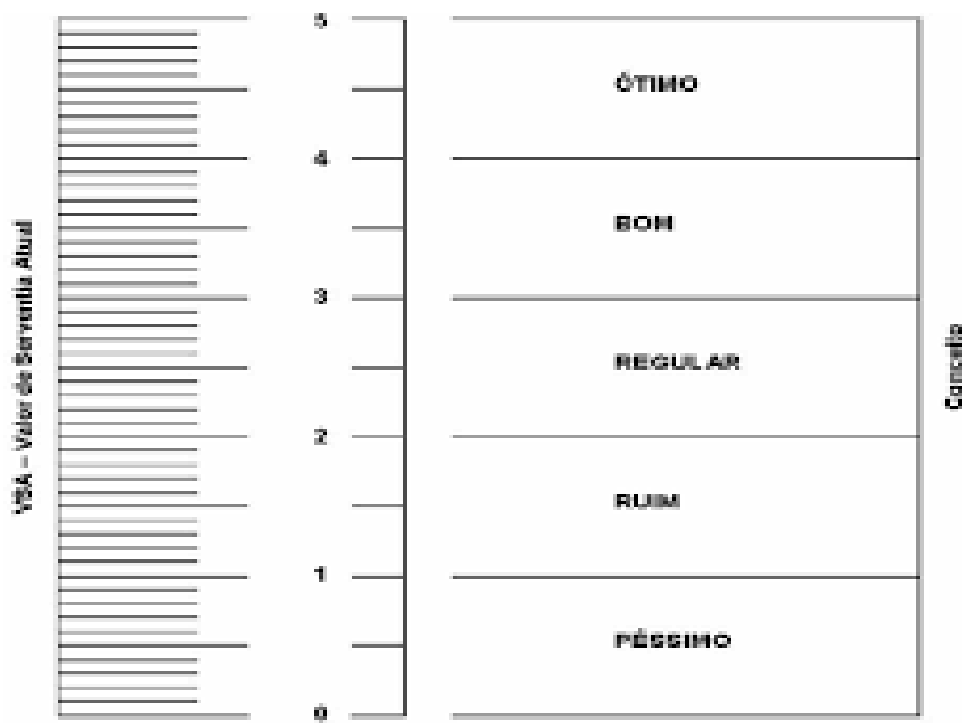

Figura 5: Ficha de Avaliação de Serventia. Fonte: DNIT, 2003.

Por fim, após a conclusão de todas as etapas, calculou-se o Valor de Serventia Atual (VSA) para o pavimento do trecho pesquisado. Enfatizando-se, que ao fim do procedimento, o valor encontrado foi comparado aos dos demais pesquisadores que participaram da vistoria, conforme recomendação da norma do DNIT (2003c).

\section{DISCUSSÃO DOS RESULTADOS}

Analisando-se os dados coletados na vistoria realizada em campo, que exprimem as condições do pavimento quanto às patologias existentes e quanto ao conforto e segurança que este apresenta, foi possível estabelecer algumas considerações pertinentes ao tema em questão.

Corroborando com Moura (2014), tem-se que, em geral, as causas das patologias no pavimento estão relacionadas, principalmente, às falhas de projeto, tanto as que antecedem a execução quanto no decorrer da mesma. Segundo Cavalcante et al. (2012), tais falhas, ocasionam a degradação prematura do pavimento, que em Manaus tem seu processo de falência notadamente acelerado pelas altas temperaturas e elevado índice pluviométrico.

\subsection{Análise das trincas e fissuras}

No trecho estudado, observou-se quase que em todo o trajeto a presença de trincas e fissuras, que são defeitos de severidade média. Estes por suas vez estão dispostos em forma transversal e longitudinal (Figura 6), em bloco e também nas denominadas "couro-de-jacaré” (Figura 7).
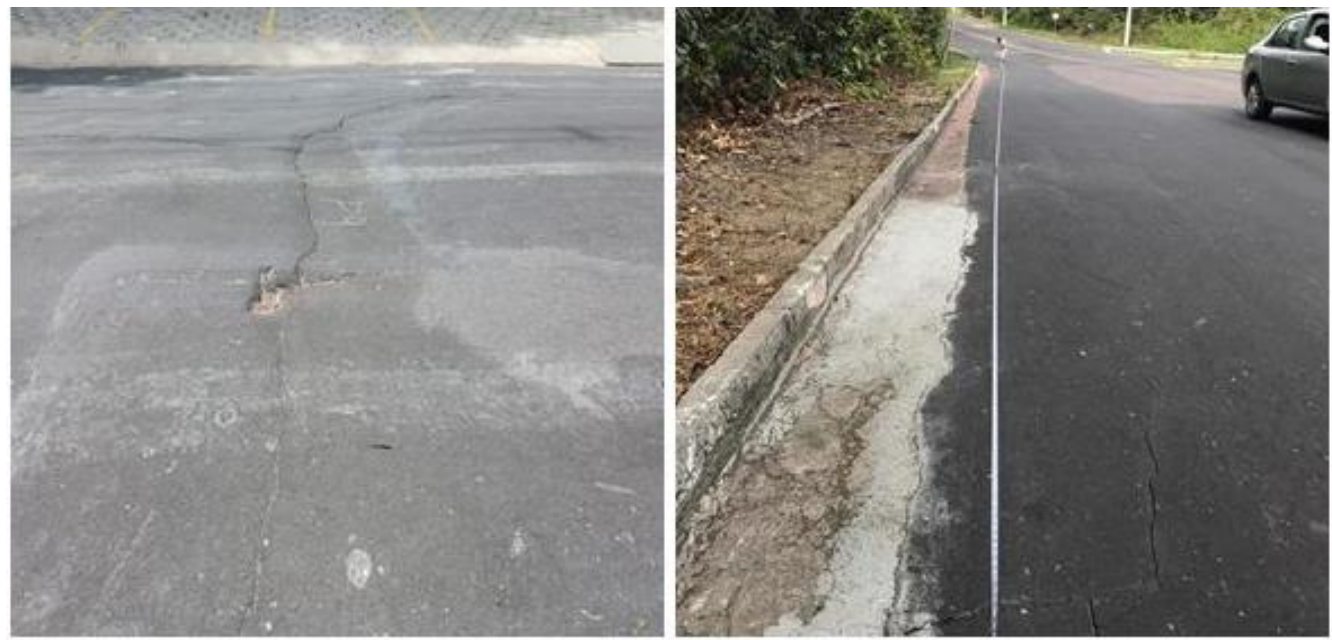

Figura 6: Manifestação de trinca transversal e longitudinal na camada de rolamento. Fonte: Autores, 2018. 

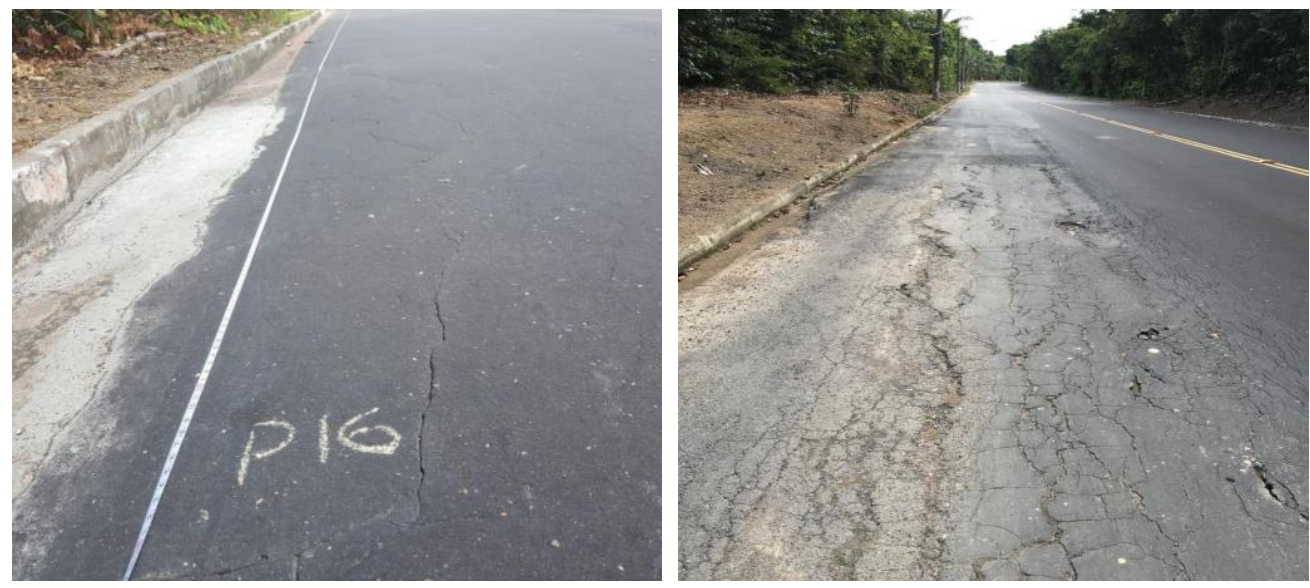

Figura 7: Camada asfáltica com manifestação de trinca em bloco e trinca "couro de jacaré". Fonte: Autores, 2018.

Em geral, o surgimento de trincas e fissuras está ligado à diversas causas, no entanto, ressalta-se para os problemas estruturais do pavimento, causados por enfraquecimento das camadas, principalmente, nos períodos de chuva, e para a contração devida a alta temperatura da região, que podem ser vistas nas camadas de rolamento com espessuras insuficientes. Conforme Ribeiro (2017), o reparo destes defeitos depende da severidade, podendo ser resolvido com a selagem das trincas, melhoria da drenagem, ou substituição localizada da sub-base, base e/ou revestimento.

\subsection{Análise dos remendos}

Os remendos são originados da demanda de correções paliativas que visam sanar provisoriamente as irregularidades das superfícies dos pavimentos. A sua avaliação quanto ao nível de severidade está relacionado diretamente com o defeito apresentado. Na via vistoriada vislumbrou-se grande quantidade de remendos, muitas vezes estabelecidos a distâncias muito curtas um do outro, conforme destacado na (Figura 8).

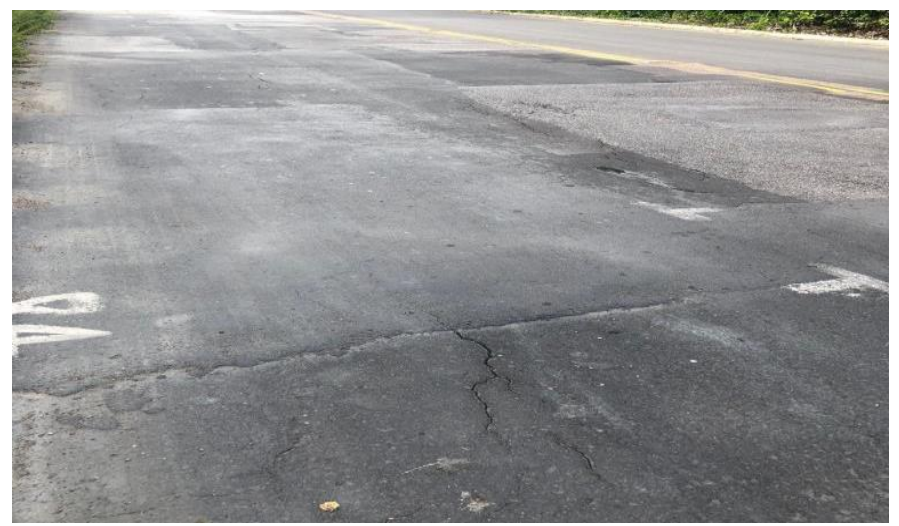

Figura 8: Revestimento asfáltico apresentando remendos. Fonte: Autores, 2018.

\subsection{Análise de panelas}

Também denominadas de buracos, as panelas são cavidades com tamanhos variáveis que ocorrem nos revestimentos dos pavimentos, podendo, sob efeito da fadiga suscitada pelo tráfego, alcançar camadas inferiores. As causas dessas patologias estão ligadas, em grande parte, por falta de aderência entre as camadas, causando o desplacamento das mesmas.

No caso das vias da UFAM, verificou-se em todos os trechos a presença destas patologias (Figura 9), que possivelmente são causadas pela má adesividade entre as camadas da superfície, como também, pela ineficiência da drenagem superficial presente e pela composição em alguns trechos em AAUQ da camada de rolamento que conforme Cavalcante et al. (2012), não resiste bem às solicitações de esforços no município de Manaus devido a fatores climáticos da região. 

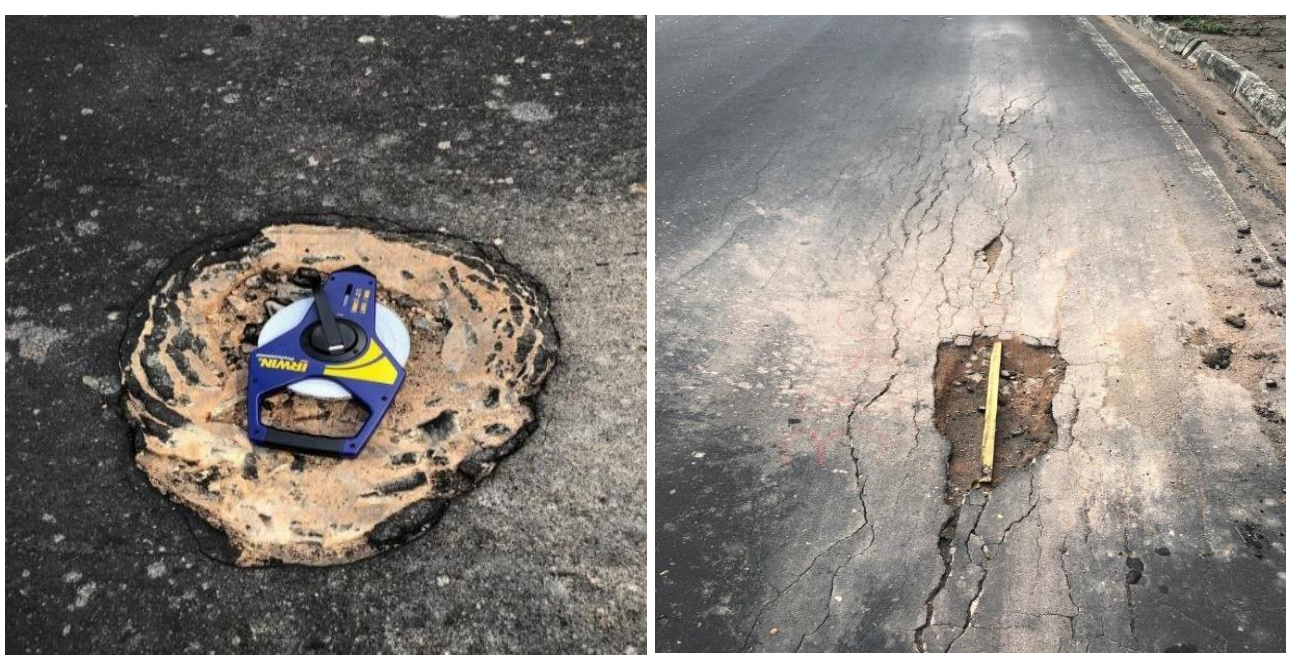

Figura 9: Panelas presentes em alguns trechos das vias. Fonte: Autores, 2018.

\subsection{Análise do desgaste}

Conforme DNIT (2003), desgaste é o efeito do arrancamento progressivo do agregado do pavimento, caraterizado pela aspereza superficial no revestimento. A CNT (2018), descreve como as principais causas a falha de adesividade liganteagregado, presença de água aprisionada e sobreposição de vazios da camada de revestimento, gerando deslocamento de ligante. Sendo assim, destaca-se o desgaste do pavimento do campus (Figura 10), que pode ser presenciado em praticamente toda a sua extensão.

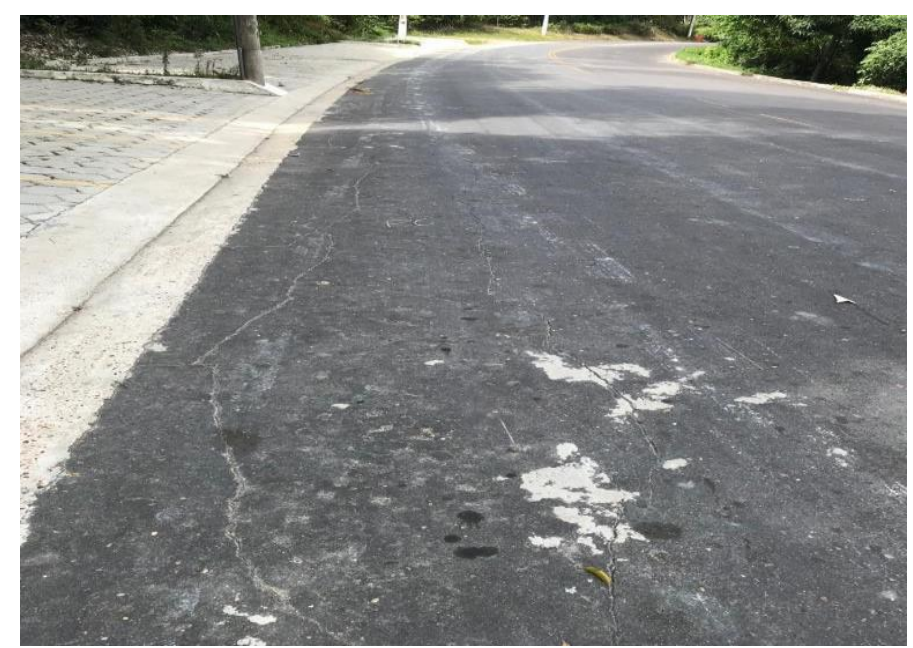

Figura 10: Revestimento asfáltico apresentando desgaste. Fonte: Autores, 2018.

A intensa presença de desgaste no sistema viário do Campus pode estar ligada ao fato de que o pavimento tenha ultrapassado o tempo de serviço para o qual foi projetado. Segundo os dados obtidos na prefeitura do Campus, projetouse o pavimento em questão para uma vida útil de 10 anos, no entanto, passado tal período fez-se apenas correções pontuais, e não a recuperação total, como recomenda as diretrizes construtivas de pavimentos.

\subsection{Análise dos escorregamentos}

Vislumbrou-se escorregamentos em alguns subtrechos específicos (Figura 11), mais precisamente, nos subtrechos 4, 5, 6 e 7. Segundo a CNT (2018) o deslocamento em relação à camada subjacente do pavimento com aparecimento de fendas em meia-lua é denominado de escorregamento. 


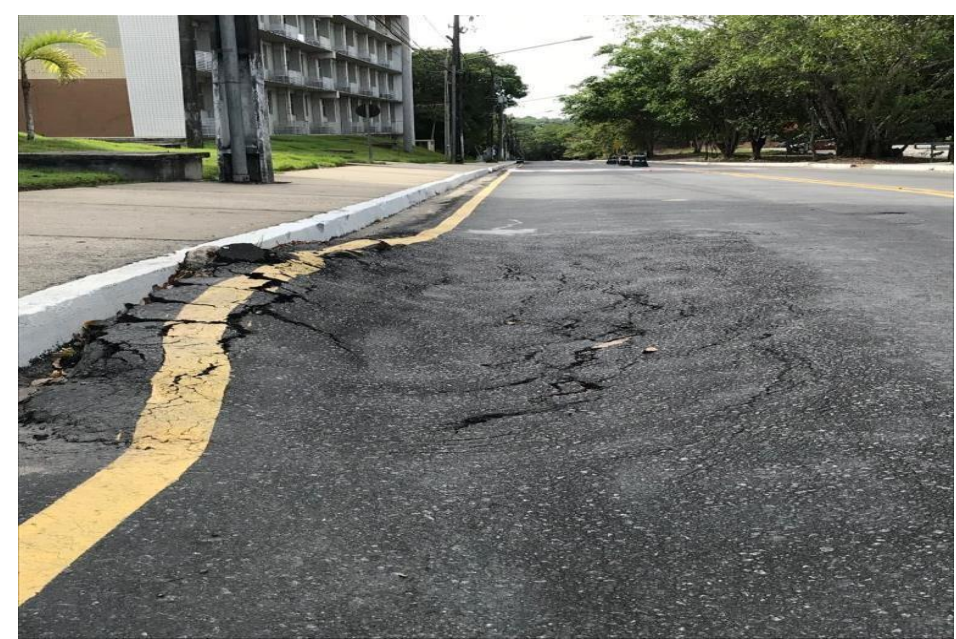

Figura 11: Escorregamento do pavimento. Fonte: Autores, 2018.

Notadamente, os escorregamentos concentram-se nas laterais das vias, o que indica falhas construtivas, principalmente, quanto a aplicação de pintura de ligação entre as camadas e utilização de massa asfáltica com baixa resistência.

\subsection{Análise dos afundamentos}

Embora menos recorrente que outras patologias levantadas, os afundamentos estão presentes em todos os subtrechos (Figura 12), alguns, visivelmente com mais notoriedade.

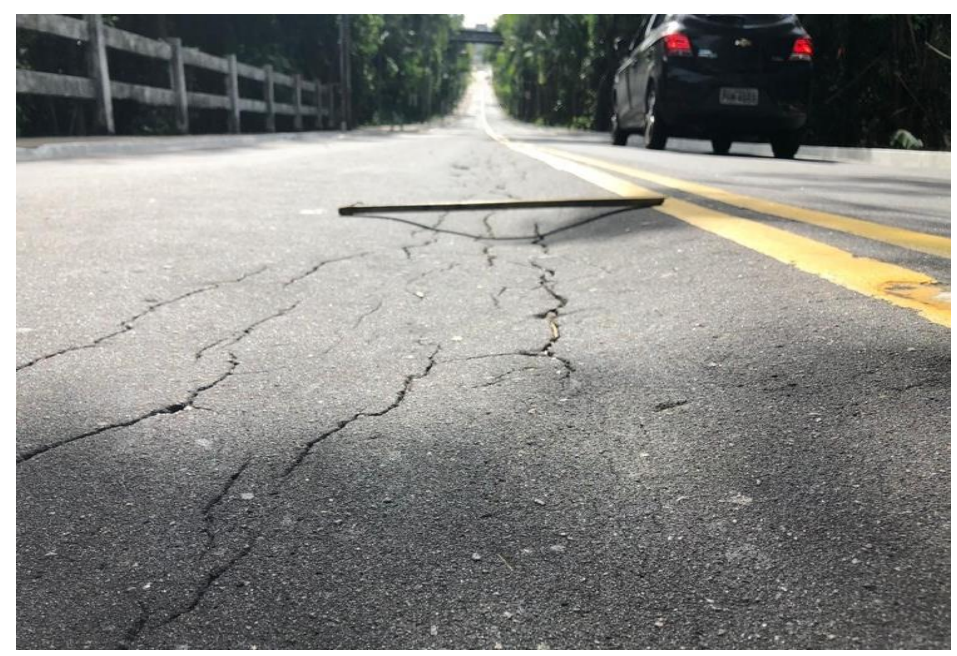

Figura 12: Afundamento no subtrecho 6. Fonte: Autores, 2018.

Nas especificações do DNIT (2003a), tem-se que afundamento é toda deformação permanente caracterizada pela depressão da superfície do pavimento, podendo ainda, ser acompanhada, ou não, de solevamento, apresentando-se sob a forma de afundamento plástico ou de consolidação.

\subsection{Análise geral e respectivo valor de serventia do pavimento do sistema viário da UFAM}

No trecho estudado observou-se manifestações patológicas dos mais diversos tipos e grau de severidade. Considerandose que o pavimento, tendo ultrapassado sua vida útil e, estruturalmente apresenta em sua composição materiais que não reagem de forma satisfatória aos esforços de tráfego, principalmente, às ações decorrentes das características regionais como o clima e chuvas intensas, tem-se uma frequência alta de recorrência de defeitos.

Durante o período de vistoria in loco, observou-se que a via recebe grandes fluxos de veículos, mostrando-se altamente solicitada. Verificou-se ainda que a deterioração do pavimento se dá, notadamente, com mais intensidade nas laterais da 
estrutura. $\mathrm{O}$ que possivelmente pode ser explicado pelo fato das faixas laterais serem as mais afetadas pelas falhas de drenagem, como também, pelo fato de terem sido executas de maneira diferente das faixas centrais.

Embora toda a extensão da malha viária apresente indícios de degradação e/ou patologias estabelecidas, alguns dos subtrechos avaliados mostram-se em melhores condições que os demais. Tal fato pode ser evidenciado por meio da avaliação subjetiva realizada em cada um dos subtrechos, conforme recomendações do DNIT (2003c), que estabelece as diretrizes para o cálculo do VSA. Sendo assim, elaborou-se a (Tabela 1) com os valores de VSA de cada subtrecho, e o valor do VSA médio, como medida para todo o trecho percorrido.

Tabela 1 - Valores de Serventuia Atual por subtrecho. Fonte: Autores, 2018.

\begin{tabular}{c|c|c}
\hline Subtrecho & $\begin{array}{c}\text { Valor de Serventia } \\
\text { Atual (VSA) }\end{array}$ & Classificação \\
\hline 1 & 2,25 & Regular \\
\hline 2 & 2,75 & Regular \\
\hline 3 & 3,25 & Bom \\
\hline 4 & 2,75 & Regular \\
\hline 5 & 2,75 & Regular \\
\hline 6 & 1,00 & Ruim \\
\hline 7 & 1,00 & Ruim \\
\hline VSA Médio: & 2,25 & Regular \\
\hline
\end{tabular}

Verifica-se, portanto, que conforme os VSAs determinados, o pavimento do sistema viário do campus da UFAM apresenta-se em geral como regular, no entanto, a variar, nominalmente, de ruim a bom.

\section{CONCLUSÕES}

A partir do levantamento realizado, foi possível classificar a via quanto ao conforto e segurança, que em uma avaliação geral o resultado obtido é regular, conforme o Valor de Serventia Atual. No entanto, verificou-se em alguns trechos do sistema viário do campus há presença de patologias que necessitam de intervenções técnicas adequadas. Um vez que a segurança e o conforto dos usuários estão comprometidos.

Ainda ao que concerne aos dados e informações levantadas, pôde-se perceber que a administração do Campus da UFAM, embora reconheça a necessidade de manutenção e restauração do pavimento do seu sistema viário, não subsidia serviços fundamentados em preceitos técnicos, ambientais ou econômicos, optando pela execução de manutenções corretivas, que sucedem o surgimento das patologias propriamente ditas, ao invés, de priorizarem a realização de manutenções preventivas, que precedem-se a ocorrência dos defeitos.

\section{REFERÊNCIAS}

BALBO, J. T. Pavimentação asfáltica: materiais, projeto e restauração. 558 p. Oficina de Textos, 2007.

BERNUCCI, L. B; MOTTA, K. d; CERATTI, J. A. P.; SOARES, J. B. Pavimentação Asfáltica: formação básica para engenheiros. Rio de Janeiro, 2008.

CAVAlCANTE, D. G; SOUZA, R. J. Q; CUNHA, T. M. F; FROTA, C. A. Estudo da Resistência à Tração de Misturas Asfálticas utilizando Ligante Modificado com SBS e Agregados Sintetizados de Argila Calcinada para a Construção das Vias Urbanas de Manaus-AM. In: Anais... Congresso de Infraestrutura de Transportes, 4. São Paulo, 2010.

CAVAlCANTE, D. G; CRISÓSTOMO, P. H. S; SILVA, L. C. P; SOUZA, R. J. Q; GUIMARÃES, D. M. D; FROTA, C. A. Levantamento Visual das Patologias na Cidade de Manaus-AM. Revista Teoria e Prática na Engenharia Civil. n.19. p.77-87. Maio, 2012.

BARBOSA, C.A. Tese de Dissertação de Mestrado: Misturas do Tipo Stone Matrix Asphalt (SMA) com agregados alternativos, Fibra do Curauá e nanomaterial. Manaus, 2016. 
CNT. Confederação Nacional de Transportes. Pesquisa CNT de Rodovias: Relatório Gerencial. Brasília: CNT, 2015.

CNT. Confederação Nacional de Transportes. Pesquisa CNT de Rodovias: Relatório Gerencial. Brasília: CNT, 2016.

CNT. Confederação Nacional de Transportes. Pesquisa CNT de Rodovias: 13 principais defeitos do pavimento. Brasília: CNT, 2018.

DNIT. Departamento Nacional de Infraestrutura de Transportes 005/2003: Defeitos nos pavimentos flexíveis e semi-rígidos - Terminologia. Rio de Janeiro: DNIT, 2003a.

DNIT. Departamento Nacional de Infraestrutura de Transportes 008/2003: Levantamento visual continuo para avaliação da superfície de pavimentos flexíveis e semi-rígidos - Procedimento. Rio de Janeiro: DNIT, 2003 b.

DNIT. Departamento Nacional de Infraestrutura de Transportes 009/2003: Avaliação subjetiva da superfície de pavimentos flexíveis e semi-rígidos - Procedimento. Rio de Janeiro: DNIT, 2003c.

DNIT. Departamento Nacional de Infraestrutura de Transportes. Manual de Restauração de Pavimentos Asfálticos. Rio de Janeiro: DNIT, 2006.

DOMIngueS, F. A. A. Manual para Identificação de Defeitos de Revestimento Asfálticos de Pavimentos. São Paulo, 1993.

DUTRA, M. O.; ASSAYAG, E. S.; ANDRADE, J. B. L. Valoração da Floresta do Campus da Universidade Federal do Amazonas pelo Método Contingente. Manaus, 2018.

GONÇALVES, F. P. O Desempenho dos Pavimentos Flexíveis. Porto Alegre, 1999.

FrotA, C. A; SILVA, C. L; NUNES, F. R. G. Análise do Comportamento Mecânico de Misturas Asfálticas Confeccionadas com Agregados Sintéticos de Argila Calcinada. In: Anais... Jornadas Luso-Brasileiras de Pavimentos: Políticas e Tecnologias, 5. v. 047. Recife, 2006a.

FROTA, C. A; MELO, D. M; NUNES, F. R. G. Análise do Comportamento Mecânico de Misturas Asfálticas com Resíduo Processado da Construção Civil. In: Anais... Jornadas 108 Luso-Brasileiras de Pavimentos: Políticas e Tecnologias, 5. Recife, 2006b.

FROTA, C. A; MELO, D. M; SILVA, C. L; NUNES, F. R. G; Santos, M. G. R. Alternativa ao uso do Seixo Rolado, como Agregado Graúdo em Misturas Asfálticas, para o Município de Manaus. In: Anais... Congresso de InfraEstrutura de Transportes, 1. São Paulo: ANDIT, 2007a.

FrotA, C. A; MELO, D. M; SILVA, C. L; NUNES, F. R. G. Avaliação do Atrito em Misturas Asfálticas Utilizando Resíduos de Construções e Demolições em Manaus- AM. In: Anais... Jornadas Luso-Brasileiras de Pavimentos, 6. Porto: FEUP, 2007b.

FROTA, C. A; MELO, D. M; D'ANTONA, D. M. Influência da Temperatura nas Misturas Asfálticas com Resíduos de Construção e Demolição. In: Anais... Jornadas Luso-Brasileiras de Pavimentos, 6. Porto: FEUP, 2007c.

FROTA, C. A; NUNES, F. R. G; SILVA, C. L; MELO, D. M; SANTOS, M. G. R. Desempenho Mecânico de Misturas Asfálticas confeccionadas com Agregados Sintéticos de Argila Calcinada. Revista Cerâmica. n. 53. p. 255-262. 2007d.

MOURA, E. Transporte e Obras de Terra: Apostila de Projeto de Pavimento. São Paulo, 2014.

RIBEIRO, A. J. A.; BEZERRA, F. R. D.; NETO, J. C. P. Metodologia Prática de Avaliação no Pavimento Asfáltico em Avenida de Fortaleza - Ce. Fortaleza, 2017.

SENÇO, W. de. Manual de técnicas de pavimentação. São Paulo: Pini, 2008. 